\title{
Predicting Job Seeking Frequency and Psychological Well-Being in the Unemployed
}

\author{
KARL K. K. WIENER \\ TIAN P. S. OEI \\ PETER A. CREED
}

Unemployed $(n=118)$ and employed $(n=120)$ people were contrasted on variables of well-being, confidence, and employment commitment. The unemployed scored lower on the General Health Questionnaire (Goldberg, 1972) and the General Self-Efficacy Scale (Sherer et al., 1982). No differences were identified on levels of employment commitment. For the unemployed sample, predictors of job-seeking behavior and well-being were then examined. Intention to seek work predicted job-seeking behavior, while self-efficacy, employment commitment, and intentions to seek work predicted well-being. Results are discussed in light of current theories of job seeking behavior, and recommendations are made for practice.

Unemployment remains a major social problem. It has been a reoccurring problem throughout this century and a feature of industrialized countries since the early to mid-1970s. The current unemployment rate in Australia hovers between $8 \%$ and 9\%, although some estimate that there are large numbers of "hidden unemployed" that place this figure much higher (Sheehan, 1980). The official unemployment rate of $8 \%$ to $9 \%$ equates to some 800,000 people out of work, with approximately one third of these being longterm $\geq 12$ months) unemployed (Australian Bureau of Statistics [ABS], 1997a, 1997b).

It is now well documented that for many the experience of unemployment brings with it problems related to personal effectiveness and general well-being (Winefield, 1995). For example, when the unemployed are compared with those in employment, they report greater psychological distress (Henwood \& Miles, 1987; Ullah, Banks,

Karl K. K. Wiener is a doctoral student, and Tian P. S. Oei is a professor, both in the Department of Psychology at the University of Queensland in Australia. Peter A. Creed is a senior lecturer in the School of Applied Psychology at Griffith University, Gold Coast, Australia. Correspondence regarding this article should be sent to Peter A. Creed, School of Applied Psychology, Griffith University, PMB 50, Gold Coast Mail Centre, Australia 9726 (e-mail: p.creed@mailbox.gu.edu.au). 
\& Warr, 1985), higher levels of depression (Branthwaite \& Garcia, 1985; Feather \& O'Brien, 1986), and lower levels of self-esteem (Muller, Hicks, \& Winocur, 1993). Furthermore, longitudinal studies have been able to demonstrate that negative effects associated with unemployment emerge when people lose their jobs and are by and large not associated with individuals with fewer skills or personal resources who "drift" into joblessness (Patton \& Noller, 1990; Winefield \& Tiggemann, 1990).

Several theories have been proposed to account for the poorer wellbeing of the unemployed. Jahoda (1982) argued that, along with manifest benefits (e.g., income), work has latent benefits (e.g., time structure, social contact) that are important for well-being. It is the loss of these latent benefits when the individual becomes unemployed that leads to a deterioration in mental health. Fryer (1986), on the other hand, has argued that it is the economic deprivation and poverty that frustrate personal agency and negatively affect psychological health. However, it is unlikely that poor well-being can be fully explained by either one of these approaches alone. Behavior is influenced by the environmental context of the individual as well as by internal individual processes. Furthermore, other variables, such as ability, personality, and previous life experiences are likely to influence individual processes and the individual's reaction to the environment.

There is much less evidence regarding the relationship between well-being and job seeking behaviors. Vinokur and Caplan (1987) found that unsuccessful job seeking was associated with poor psychological health. These authors also found that the individual's expressed intention to try hard was the best predictor of job seeking behavior. An early theory (Schwab, Rynes, \& Aldag, 1987) proposed that strength of job search was a function of well-being (e.g., self-esteem) and the need for a job (driven by financial requirements). More recently, social support and the personality variable of conscientiousness have been identified as predictive of job seeking behavior (Wanberg, Watt, \& Rumsey, 1996).

Much of the literature investigating the negative effects of unemployment has given attention to examining a large number of individual and situational variables that moderate the individual's reaction to unemployment and influence his or her capacity to cope with joblessness and the return-to-work process. Self-efficacy (Bandura, 1997) has been investigated in this light. Bandura (1986) defined self-efficacy as

people's judgments of their capabilities to organize and execute courses of action required to attain designated types of performances. It is concerned 
not with the skills one has but with judgments of what one can do with whatever skills one possesses. (p. 391)

It has been demonstrated experimentally that levels of self-efficacy are directly linked to subsequent performance, such that higher levels of perceived efficacy lead to relatively higher levels of performance (Bandura, Reese \& Adams, 1982; Wood \& Bandura, 1989). In applied settings, high levels of self-efficacy have been associated with increased job search behavior (Kanfer \& Hulin, 1985), and low levels of self-efficacy have been associated with withdrawing from the job search process (Rife \& Kilty, 1990). Eden and Aviram (1993) demonstrated that self-efficacy influenced the motivation of unemployed people to seek employment. They suggested that prolonged unemployment eroded selfefficacy and subsequently negatively affected the individual's effort to search for work. These authors found that raising self-efficacy caused intensification of effort and increased the unemployed individual's job seeking activity.

However, it is still not clear how important self-efficacy is in the return-to-work process for unemployed individuals. Moreover, the way well-being might interact with self-efficacy to influence unemployed people's job search behaviors or even how the unemployed differ from the employed on this dimension are not well understood. Self-efficacy has been demonstrated to be an important determinant of behavior in general, and the way it influences unemployed people when they seek to gain work needs to be understood. In this study, the role that self-efficacy plays in the individual's well-being and job seeking behavior will be examined.

Employment commitment, or the importance of work to the individual, has been identified as an important moderator of the negative psychological effects of unemployment. Greater distress is experienced by unemployed people who have higher levels of employment commitment (Feather, 1990; Warr, 1987). Some research has suggested that even after long periods of unemployment most unemployed people still would prefer to be in paid work (Warr \& Jackson, 1984). In relation to job seeking behavior, low employment commitment correlates strongly with lack of purpose and time structure, both needed factors in job search behavior (Feather, 1990). High levels of employment commitment have also been associated with more active job search behavior (Rowley \& Feather, 1987). The individual's intention to seek work has also been shown to be one of the main determinants in any subsequent job seeking behavior and has been shown to be influenced by the self-efficacy of the individual (Vinokur \& Caplan, 1987). These same authors also identified that perceived need for work may be positively related to job seeking. 
It is unclear whether the length of unemployment of the individual influences job seeking behavior. Feather (1982) demonstrated that people unemployed for long periods of time showed a decline in job search behavior when compared with short-term unemployed. However, this result was not confirmed by Warr and Jackson (1984), who found no association between job seeking behavior and the jobless period. In a later study, Feather and O'Brien (1987) identified a positive relationship between job seeking behavior and length of time unemployed.

The intention of this study was to test a model that proposes that job seeking behavior (operationalized by frequency of job search), is influenced by the individual's well-being, self-efficacy, commitment to being employed, need for a job, behavioral intentions, and length of unemployment. It is also possible, given the methodology used in this research project, to test for the reciprocal relationship between well-being and job search behaviors. The general question asked here relates to the impact on well-being of the job seeking attitudes and behaviors of the unemployed person.

This article reports on the differences between a group of unemployed and a group of employed individuals on variables of psychological well-being, self-efficacy, and employment commitment. Previous studies have regularly shown that unemployed people report poorer well-being than those in jobs, and this was expected with these samples. There is less certainty as to the differences on the dimensions of Self-Efficacy and Employment Commitment. Second, the unemployed sample is examined in relation to the determinants of job seeking behavior and well-being. Specifically, it is postulated that expressed need for a job, behavioral intentions, and length of unemployment, along with well-being and self-efficacy will predict job seeking behaviors, and that well-being in turn will be influenced by these same variables.

\section{METHOD}

\section{Participants}

Participants in the study were 118 unemployed and 120 employed adults. The 118 unemployed participants were seeking full-time work and were registered with the national employment agency in Brisbane, Australia. This group consisted of 79 men (67\%) and $39(33 \%)$ women, with a mean age of 33 years $(S D=13)$, and a range of 18 to 62 years. The 120 employed subjects were public service employees who worked in the national employment agency. This group consisted of 50 men 
$(42 \%)$ and 70 women $(58 \%)$ whose mean age was 35 years $(S D=10$; range 18-61 years).

\section{Procedure}

Each group of participants was a sample of convenience. Members of the unemployed group were given a survey form when they attended the employment agency to receive information about return-to-work initiatives. One hundred and eighteen unemployed individuals of the 120 who were given the survey forms completed them. Members of the employed group were agency staff members who volunteered to participate in the study. One hundred and sixty survey forms were distributed to this group, and 120 copies were completed and returned.

The survey forms asked participants for demographic information (i.e., age, sex, level of education, and length of unemployment for the unemployed sample), and to complete the 12-item General Health Questionnaire, the General Self-Efficacy Scale, and the Employment Commitment Scale. The unemployed participants were also asked to indicate the measures they used to seek work, how confident they were of getting work, how much they felt they needed a job, and how hard they intended to try to get work.

\section{Measures}

General Health Questionnaire (GHQ). The 12-item version of the GHQ (Goldberg, 1972) was used to measure psychological distress. This version has been recommended by Banks, Jackson, Stafford, and Warr (1980) for use in occupational studies and has been used widely by researchers in this area (e.g., Bond \& Feather, 1988; Warr, 1987). The scale is concerned with two major phenomena: first, the inability to carry out one's normal healthy functions, and second, the appearance of new experiences of a distressing nature. Sample items included, "Have you recently lost much sleep over money?" and "Have you recently felt constantly under strain?" Responses were rated on a 4-point Likert-like scale using discriminators such as better than usual, same as usual, less than usual, and much less than usual, and scored 0-0-1-1. This method of scoring better discriminates between those with clinical problems ("cases") and those without clinical problems ("normals") on psychological distress. Higher scores indicate more distress. Sound reliability and validity data are provided for the $\mathrm{GHQ}$ in the manual (Goldberg \& Williams, 1991), and adequate reliability levels have been found with unemployed populations. Rowley and Feather (1987), for example, reported an internal reliability of 0.89 with their unemployed participants. 
General Self-Efficacy Scale (GSE). The 17-item GSE (Sherer et al., 1982) was used as a measure of general confidence. For many, feelings of competency are tied to the workplace and to the work done. Loss of a job, or failure to enter work, can impair an individual's belief in his or her capacity to tackle and perform tasks. The GSE has been shown to be a good predictor of behavioral initiation and persistence. It has successfully predicted success in vocational, educational, and military settings (Woodruff \& Cashman, 1993). Items in the GSE focus on the individual's reported willingness to initiate behavior, to expend effort in completing the behavior, and to persist in the face of adversity. Sample items include, "I give up easily," and "When I make plans, I am certain I can make them work." Responses are rated on a 6-point Likert-like scale using end points of strongly disagree and strongly agree. Higher scores indicate higher levels of confidence. Validity and reliability data are provided by the developers (Sherer et al., 1982) and by Woodruff and Cashman. Internal reliabilities reported by these authors were 0.86 and 0.84 , respectively.

Employment Commitment Scale (ECS). The 8-item ECS was used to provide a measure of each participant's commitment to having a job. This construct can be used to indicate the level of motivation a person has to be in the workforce. Participants were asked to respond to questions on a 6-point Likert-like scale that had response categories ranging from strongly agree to strongly disagree. Questions included the following: "I really must get a job, or I'll lose my self-respect," and "Being unemployed is about the worst thing that ever happened to me." Higher scores indicate higher levels of commitment. The ECS was originally developed by Warr and Jackson (1984) and was modified by Rowley and Feather (1987) to suit the Australian context. Rowley and Feather reported an internal reliability of 0.85 with their sample of unemployed Australians. The ECS was used with both the employed and unemployed groups. The scale was slightly altered for the employed group. For example, "I hate being on the dole" was changed to "I would hate being on the dole," and "Being unemployed is about the worst thing that ever happened to me" was altered to "Being unemployed would be about the worst thing that ever happened to me."

Methods of Job Seeking Behavior (FREQ). Unemployed participants were asked to indicate the number of times they had used each of the following job search methods in the past fortnight: employment agency notice boards, newspaper, telephoning or visiting employers, writing to employers, placing a personal advertisement in a newspaper, asking friends and relatives, or other (they were asked to state the method). The responses were aggregated to provide an overall job search frequency score for the 
previous 2 weeks. Similar questions were used by Rowley and Feather (1987).

Specific Employment Confidence (CONF). Unemployed participants were asked to indicate how confident they were of obtaining paid work in the next 6 months. This single item was rated on a 6-point Likert-like scale with end points of not confident and very confident. Higher scores indicated more confidence. Similarly phrased items were used in previous studies by Feather and O'Brien (1987) and Feather (1982).

Employment Need (NEED). Unemployed participants were asked to indicate how strongly they felt they needed a job. This single item was rated on a 6-point Likert-like scale with end descriptors of do not really need $a j o b$ and desperate to have $a j o b$. Higher scores indicated stronger need. This item was a measure similar to that used by Feather and O'Brien (1987).

Job Search Intent (INTENT). Unemployed participants were asked to indicate how hard they intended to try to get a job over the next 3 months. This item was also rated on a 6-point Likert-like scale with end points of not hard at all and extremely hard. Higher scores indicated higher levels of intended effort. A similar item was used in a previous study by Vinokur and Caplan (1987).

\section{RESULTS}

\section{Comparison Between Employed and Unemployed Samples}

In this section, the unemployed and employed samples are contrasted on the demographic and dependent variables. One-way analysis of variance (ANOVA) and chi-square analyses were used to test for differences between the unemployed and the employed samples. The two groups were well matched on the variable of age. However, the unemployed group had fewer years of schooling than the employed sample, $\chi^{2}(5)=44.99, p<.01$, and contained disproportionately more men, $\chi^{2}(1)=14.07, p<.01$.

The unemployed and the employed groups did not differ significantly on the employment commitment variable. The unemployed group reported poorer psychological health, as measured by the GHQ, $F(1,228)=6.04, p<.05$, and lower levels of general self-efficacy, as measured by the GSE, $F(1,210)=18.90, p<.01$. Means and standard deviations are reported in Table 1.

These analyses were useful because they confirmed that the unemployed in the sample used in this study were typical of unemployed populations. The unemployed group had lower levels of education, poorer psychological health, and less confidence than 


\section{TABLE 1}

Means and Standard Deviations for the Employed and Unemployed Groups on Demographic and Dependent Variables

\begin{tabular}{|c|c|c|c|c|c|c|c|}
\hline \multirow[b]{2}{*}{ Variable } & \multicolumn{3}{|c|}{ Employed } & \multicolumn{3}{|c|}{ Unemployed } & \multirow[b]{2}{*}{$p$} \\
\hline & $n$ & $M$ & SD & $n$ & $\boldsymbol{M}$ & $S D$ & \\
\hline Age & 120 & 35.34 & 10.30 & 109 & 33.01 & 12.60 & ns \\
\hline $\begin{array}{l}\text { General Health } \\
\text { Questionnaire }\end{array}$ & 120 & 2.28 & 3.05 & 110 & 3.35 & 3.56 & $<.05$ \\
\hline $\begin{array}{l}\text { General Self- } \\
\text { Efficacy Scale } \\
\text { Employment }\end{array}$ & 102 & 82.11 & 11.84 & 110 & 72.95 & 17.97 & $<.01$ \\
\hline $\begin{array}{l}\text { Employment } \\
\text { Commitment Scale } \\
\text { Job Search }\end{array}$ & 119 & 35.16 & 8.45 & 109 & 36.05 & 8.06 & ns \\
\hline $\begin{array}{l}\text { Frequency } \\
\text { Confidence in }\end{array}$ & \multicolumn{3}{|c|}{ no measure taken } & 103 & 13.83 & 9.94 & - \\
\hline Obtaining Work & “ & “ & “ & 110 & 3.26 & 1.72 & - \\
\hline $\begin{array}{l}\text { Expressed Need } \\
\text { for Work } \\
\text { Intention to Seek }\end{array}$ & “ & “ & “ & 110 & 4.51 & 1.26 & - \\
\hline $\begin{array}{l}\text { Work } \\
\text { Length of }\end{array}$ & “ & “ & “ & 109 & 4.72 & 1.24 & - \\
\hline $\begin{array}{l}\text { Unemployment } \\
\text { in Weeks }\end{array}$ & $“$ & " & “ & 108 & 105.02 & 105.92 & - \\
\hline
\end{tabular}

employed populations. This unemployed sample also contained more men than women, which is typical of the general unemployed. Secondly, comparing the two groups demonstrated that the unemployed sample had levels of commitment to work similar to those in paid employment.

\section{Intercorrelations}

Table 2 reports the intercorrelations among the demographic and the dependent variables being investigated in the study. For wellbeing, there were significant associations between scores on the GHQ and need for employment $(r=.20, p<.05)$, and GHQ and self-efficacy $(r=-.34, p<.01)$; those with higher levels of psychological distress had a higher need for employment but lower levels of confidence. For general self-efficacy, there were significant associations between GSE and employment commitment $(r=.30, p<.01)$, specific confidence in obtaining work $(r=.44, p<.01)$, need for work $(r=.22, p<.05)$, and intentions to look for work $(r=.28, p<.01)$. Those with higher levels of general self-efficacy, having had a higher commitment to work and being more confident about getting work, expressed a higher 
need for work and signified greater intention to seek work. For employment commitment, there were significant associations between ECS and frequency of job search $(r=.31, p<.01)$, confidence about job search $(r=.28, p<.05)$, need for work $(r=.55, p<.01)$, and intention to seek work $(r=.40, p<.01)$, with those with higher levels of employment commitment reporting more frequent job search efforts, more confidence in their job search, more need for work, and stronger intentions to seek work. Frequency of job search was significantly and positively associated with all of the employment variables (employment confidence, $r=.29, p<.05$; employment need, $r=$ $.36, p<.01$; job search intent, $r=.43, p<.01)$. Age was associated with confidence in obtaining work $(r=-.43, p<.01)$ and need for work $(r=-.22, p<.05)$ with older unemployed people having less confidence in obtaining work, but also expressing less need for work. Lastly, length of unemployment was significantly associated with GSE $(r=-.24, p<.05)$, and employment confidence $(r=-.25, p<.01)$, with those longer unemployed having less general self-efficacy and being less confident about obtaining work.

\section{Prediction of Job Search Frequency}

In this section, a multiple stepwise regression analysis was used to determine the influence of the demographic and independent vari-

\section{TABLE 2}

Intercorrelations Among Demographic and Dependent Variables for Unemployed Sample, Two-Tailed Significance

\begin{tabular}{|c|c|c|c|c|c|c|c|c|c|}
\hline Variable & 1 & 2 & 3 & 4 & 5 & 6 & 7 & 8 & 9 \\
\hline $\begin{array}{l}\text { 1. Age } \\
\text { 2. UE } \\
\text { 3. GHQ } \\
\text { 4. GSE } \\
\text { 5. ECS } \\
\text { 6. FREQ } \\
\text { 7. CONF } \\
\text { 8. NEED } \\
\text { 9. INTENT }\end{array}$ & - & $.21^{*}$ & $\begin{array}{r}.06 \\
-.03 \\
-\end{array}$ & $\begin{array}{c}.01 \\
-.24^{\star} \\
-.34^{\star \star} \\
-\end{array}$ & $\begin{array}{l}-.02 \\
-.03 \\
.18 \\
.30^{\star \star} \\
-\end{array}$ & $\begin{array}{l}.10 \\
-.05 \\
.18 \\
.17 \\
.31^{\star \star} \\
-\end{array}$ & $\begin{array}{l}-.43^{\star \star} \\
-.25^{\star \star} \\
-.11 \\
.44^{\star \star} \\
.28^{\star \star} \\
.29^{\star \star} \\
-\end{array}$ & $\begin{array}{l}-.22^{\star} \\
-.15 \\
.20^{\star} \\
.22^{\star} \\
.55^{\star \star} \\
.36^{\star \star} \\
.40^{\star \star} \\
-\end{array}$ & $\begin{array}{c}.05 \\
-.05 \\
.14 \\
.28^{\star \star} \\
.40^{\star \star} \\
.43^{\star \star} \\
.35^{\star \star} \\
.47^{\star *} \\
-\end{array}$ \\
\hline
\end{tabular}

Note. $\mathrm{UE}=$ Length of Unemployment; GHQ = General Health Questionaire; GSE = General Self-efficacy Scale; ECS = Employment Commitment Scale; FREQ = Job search frequency; CONF = Confidence in Obtaining Work; NEED = Expressed Need for Work; INTENT = Intention to seek work. ${ }^{*} p<.05$. ${ }^{* *} p<.01$. 
ables as predictors of job search frequency (FREQ) of the unemployed. Nine variables (age, education, length of unemployment, selfefficacy, employment commitment, frequency of job search, confidence about obtaining work, need for work, and intent to seek work) were entered into the stepwise regression equation. A significant model fit was produced, $R^{2}=.16, \mathrm{~F}(1.97)=18.41, p<.001$. However, only intention to look for work $(\beta=.40, p<.001)$, which accounted for $16 \%$ of the variance, significantly predicted job seeking frequency and was entered into the equation.

\section{Prediction of Psychological Distress}

A multiple stepwise regression analysis was used to determine the influence of the demographic and independent variables as predictors of the psychological distress of the unemployed. Nine variables (age, education, length of unemployment, self-efficacy, employment commitment, frequency of job search, confidence about obtaining work, need for work, and intent to seek work) were entered into the stepwise regression equation. Of these, only general self-efficacy (GSE), employment commitment (ECS), and intentions to seek work (INTENT) provided significant predictions of psychological health and were entered into the equation. These three variables accounted for $22 \%$ of the variance. GSE $(\beta=-.43, p<.01)$ made the strongest contribution towards predicting GHQ, with $\operatorname{ECS}(\beta=.26, p<.01)$ and INTENT $(\beta=.23, p<.05)$ contributing smaller amounts. Summary data are reported in Table 3.

\section{DISCUSSION}

\section{Comparison Between Unemployed and Employed Groups}

The unemployed and employed samples in this study were well matched for age. As is typical of unemployed groups, the present sample had a lower level of education and contained more men than did the employed group. As expected, the unemployed sample reported higher psychological distress than did those in jobs. This finding is consistent with previous studies and confirms the strong evidence that there are differences in well-being between those in jobs and those unemployed. The two groups also differed on the measure of general self-efficacy, with the employed sample reporting higher self-efficacy, thus indicating that they enjoyed a greater belief and trust in their performance abilities than did the unemployed group. There are implications for individual and group interventions that might be generated for unemployed people. Any 
TABLE 3

Prediction of Psychological Distress (GHQ) by Demographic and Independent Variables

\begin{tabular}{lrrrr}
\hline \hline Predictor Variable & $\boldsymbol{\beta}$ & $\boldsymbol{t}$ & $\boldsymbol{p}$ & $\boldsymbol{R}^{2}$ \\
\hline General Self-Efficacy Scale & -.43 & -4.38 & $<.01$ & 0.22 \\
$\begin{array}{l}\text { Employment Commitment } \\
\text { Scale }\end{array}$ & .26 & 2.57 & $<.01$ & \\
Intention to Seek Work & .23 & 2.32 & $<.05$ & \\
\hline
\end{tabular}

Note. $\mathrm{GHQ}=$ General Health Questionnaire.

intervention must first take into account the possible low levels of well-being and self-reliance.

No differences were identified between the unemployed and the employed groups on the dimension of employment commitment. Both groups expressed a strong desire to be in paid work. These results refute suggestions that the unemployed become apathetic, adjusted to their situation, or merely do not want to work. This finding is consistent with previous reports that the unemployed maintain a strong desire to return to the workforce (Warr \& Jackson, 1984). It has also been reported that unemployed people have the same goals and see their future little differently from the rest of the community (McCrae, 1987; Willis, 1984). The evidence from the present study supports these findings and argues against those who suggest that unemployment brings with it the opportunity to reevaluate life goals and re-arrange life priorities to exclude work (Fryer \& Payne, 1984; Willis, 1979).

\section{Prediction of Job Search Behavior}

Only intention to look for work was predictive of job search frequency. This was despite simple correlations being found between job search frequency and confidence, need for work, employment commitment, and intention to look for work. This finding is consistent with earlier findings based on studies with unemployed people (Taris, Heesink, \& Feij, 1995; Vinokur \& Caplan, 1987), and consistent with expectancy theories (Feather, 1982; Fishbein \& Ajzen, 1975). Contrary to expectations, neither psychological distress, general self-efficacy, nor employment commitment played a significant role in predicting frequency of job search.

Those with high levels of psychological distress did report a high need for work. Furthermore, high efficacy unemployed people had 
low levels of psychological distress, high confidence about obtaining work, elevated employment commitment, and higher need for and intentions to seek work. There was also a significant positive correlation between level of employment commitment and job search frequency; although these variables did not reach significance in the multiple regression equation.

It is possible that unemployed people tend to ignore their psychological well-being problems, or continue to search for employment despite their poor well-being. Also, unemployed people in Australia are required to produce evidence of job seeking behavior to qualify for income support. Such a requirement might increase job seeking behaviors despite low well-being and low confidence.

Length of unemployment was not a significant predictor of job search behavior, nor was there a simple correlation between unemployment duration and intention to look for work. Other studies have shown (Taris et al., 1995) that longer-term unemployed people have less motivation to seek work. This was not the case in the present study. This is also consistent with the findings here that employment commitment for the unemployed did not differ from those with jobs. McFadyen and Thomas (1997) have suggested that motivation for job search among longer-term unemployed people is sustained by economic pressures and by their readiness to accept a wider range of employment opportunities.

\section{Prediction of Psychological Distress}

The multiple regression analysis found that general self-efficacy, employment commitment, and intention to seek work significantly predicted psychological distress, with those with poorer psychological health more likely to have lower levels of general self-efficacy, stronger employment commitment, and stronger intention to seek work. Of these three predictor variables, only employment commitment did not register a significant simple correlation with well-being. Age, length of unemployment, frequency of job seeking, confidence about finding work, and need for work did not contribute to predicting well-being. As expected, general self-efficacy contributed to the prediction of well-being. Confidence has been considered a component of well-being (Warr, 1987) and needs to be taken into account when considering the mental health status of unemployed individuals. Previous findings in studies on employment commitment and wellbeing have been inconsistent (Payne \& Hartley, 1987; Winefield, Tiggemann \& Winefield, 1990). The present study did not find a significant simple correlation between the two variables, but it has shown employment commitment to be a significant predictor of psy- 
chological health. This suggests that unemployed individuals with a high employment commitment are more likely to suffer from poor psychological health.

\section{IMPLICATIONS}

Although caution needs to be exercised when examining these results because the sample used was not random, a number of important implications can be drawn. First, in this study, intention to look for work was identified as the only predictor of job search frequency. Other studies (Vinokur \& Caplan, 1987; Wanberg, Watt, \& Rumsey, 1996) have implicated social support, financial need, dissatisfaction with being unemployed, gender, and the personality variable of conscientiousness. Financial need and dissatisfaction with employment status overlap with the variables of need and wellbeing, respectively, in the present study. Future studies will still need to clarify the role of these variables in job search behavior; in particular, consideration needs to be given to these influences across different age and subcategories of the unemployed. Previous reports into job seeking behaviors that have used a variety of unemployed samples are likely to have been inconsistent for these reasons.

Second, psychological distress was predicted by general self-efficacy, employment commitment, and intention to seek work. Clearly, psychological well-being and general self-efficacy are related constructs. Even though general self-efficacy and confidence were highly correlated in this study, future investigations will need to examine specific job search self-efficacy in relation to well-being.

Finally, there are implications in this study for the development of effective interventions for the unemployed. Well-being and confidence levels do need to be addressed by practitioners. In addition, counselors should encourage unemployed people to develop clear goals and strategies for return to work. Job seeking intentions seem to be the best indicator of future job seeking behavior, and assessment may be useful to identify those most in need of assistance.

\section{REFERENCES}

Australian Bureau of Statistics. (1997a). Labour Force Australia. Preliminary Data, July. (No 6202.0). Canberra, Australian Capital Territory: Author. Australian Bureau of Statistics. (1997b). 1997 Year Book Australia. No 97. (No 1301 .0). Canberra, Australian Capital Territory: Australian Government Printing Service.

Bandura, A. (1986). Social foundations of thought and action: A social cognitive theory. Englewood Cliffs, NJ: Prentice Hall. 
Bandura, A. (1997). Self-efficacy: The exercise of control. New York: Freeman.

Bandura, A., Reese, L., \& Adams, N. E. (1982). Microanalysis of action and fear arousal as a function of differential levels of perceived self-efficacy. Journal of Personality and Social Psychology, 43, 5-21.

Banks, M. H., Jackson, P. R., Stafford, E. M., \& Warr, P. B. (1980). Young people starting work. Social and Applied Psychology Unit Memo No. 408, University of Sheffield, Sheffield, England.

Bond, M. J., \& Feather, N. T. (1988). Some correlates of structure and purpose in the use of time. Journal of Personality and Social Psychology, 55, 321-329.

Branthwaite, A., \& Garcia, S. (1985). Depression in the young unemployed and those on Youth Opportunities Schemes. British Journal of Medical Psychol ogy, 58, 67-74.

Eden, D., \& Aviram, A. (1993). Self-efficacy training to speed reemployment: Helping people to help themselves. Journal of Applied Psychology, 78, 352-360.

Feather, N. T. (1982). Unemployment and its psychological correlates: A study of depressive symptoms, self-esteem, Protestant ethic values, attributional style, and apathy. Australian Journal of Psychology, 34, 309-323.

Feather, N. T. (1990). The psychological impact of unemployment. New York: Springer-Verlag.

Feather, N. T., \& O'Brien, G. E. (1986). A longitudinal analysis of the effects of different patterns of employment and unemployment on school-leavers. British Journal of Psychology, 77, 459-479.

Feather, N. T., \& O'Brien, G. E. (1987). Looking for employment: An expectancyvalence analysis of job-seeking behaviour among young people. British Journal of Psychology, 78, 251-272.

Fishbein, M., \& Ajzen, I. (1975). Belief, attitude, intention, and behaviour. New York: Addison-Wesley.

Fryer, D. M. (1986). Employment deprivation and personal agency during unemployment: A critical discussion of Jahoda's explanation of the psychological effects of unemployment. Social Behaviour, 1, 3-23.

Fryer, D. M., \& Payne, R. L. (1984). Pro-active behaviour in unemployment: Findings and implications. Leisure Studies, 3, 273-295.

Goldberg, D. P. (1972). The detection of psychiatric illness by questionnaire. London: Oxford University.

Goldberg, D. \& Williams, P. (1991). A User's Guide to the General Health Questionnaire. Berkshire: NFER-Nelson.

Henwood, F., \& Miles, I. (1987). The experience of unemployment and the sexual division of labour. In D. Fryer \& P. Ullah (Eds.), Unemployed people (pp. 94-110). Milton Keynes: Open University.

Jahoda, M. (1982). Employment and unemployment: A social-psychological analysis. London: Cambridge University.

Kanfer, R., \& Hulin, C. I. (1985). Individual differences in successful job searches following lay-off. Personnel Psychology, 38, 835-847.

McCrae, S. (1987). Social and political perspectives found among unemployed young men and women. In S. Hudson, S. McCrae, \& C. Wallace (Eds.), The Social World of the Young Unemployed (pp. 61-92). London: Policy Studies Institute.

McFadyen, R. G., \& Thomas, J. P. (1997). Economic and psychological models of job search behavior of the unemployed. Human Relations, 50, 1461-1484.

Muller, J., Hicks, R., \& Winocur, S. (1993). The effects of employment and unemployment on psychological well-being in Australian clerical workers: Gender differences. Australian Journal of Psychology, 45(2), 103-108.

Patton, W., \& Noller, P. (1990). Adolescent self-concept: Effects of being employed, unemployed or returning to school. Australian Journal of Psychology, 42, 247-259. 
Payne, R. L., \& Hartley, J. (1987). A test of a model for explaining the affective experience of unemployed men. Journal of Occupational Psychology, 60, 31-47.

Rife, J., \& Kilty, K. (1990). Job search discouragement and the older worker: Implications for social work practice. Journal of Applied Social Sciences, 14(1), 71-94.

Rowley, K. M., \& Feather, N. T. (1987). The impact of unemployment in relation to age and length of unemployment. Journal of Occupational Psychology, 60, 323-332.

Schwab, D. P., Rynes, S. L., \& Aldag, R. J. (1987). Theories and research on job search and choice. Research in Personnel and Human Resource Management, 5, 129-166.

Sheehan, P. (1980). Crisis in abundance. Ringwood: Penguin.

Sherer, M., Maddux, J. E., Mercandante, B., Prentice-Dunn, S., Jacobs, B., \& Rogers, R. W. (1982). The Self-Efficacy Scale: Construction and validation. Psychological Reports, 51, 663-671.

Taris, T. W., Heesink, J. A. M., \& Feij, J. A. (1995). The evaluation of unemployment and job-searching behavior: A longitudinal study. The Journal of Psychology, 129, 301-315.

Ullah, P., Banks, M., \& Warr, P. B. (1985). Social support, social pressures and psychological distress during unemployment. Psychological Medicine, 15, 283-295.

Vinokur, A., \& Caplan, R. D. (1987). Attitudes and social support: Determinants of job seeking behaviour and well being among the unemployed. Journal of Applied Social Psychology, 17, 1007-1024.

Wanberg, C. R., Watt, J. D., \& Rumsey, D. J. (1996). Individuals without jobs: An empirical study of job-seeking behavior and reemployment. Journal of Applied Psychology, 81(1), 76-87.

Warr, P. B. (1987). Work, unemployment and mental health. Oxford, England: Clarendon.

Warr, P. B., \& Jackson, P. R. (1984). Men without jobs: Some correlates of age and length of unemployment. Journal of Occupational Psychology, 57, 77-85

Willis, P. (1979). Youth unemployment and leisure opportunities. London: Department of Education and Science.

Willis, P. (1984). Youth unemployment: Thinking the unthinkable. Youth and Policy, 2, 17-36.

Winefield, A. H. (1995). Unemployment: Its psychological costs. In C. L. Cooper \& I. T. Robertson (Eds.), International Review of Industrial and Organizational Psychology. Chichester, United Kingdom: Wiley.

Winefield, A. H., \& Tiggemann, M. (1990). Length of unemployment and psychological distress: Longitudinal and cross-sectional data. Social Science Medicine, 31, 461-465.

Winefield, A. H., Tiggemann, M., \& Winefield, H. R. (1990). Factors moderating the psychological impact of unemployment at different ages. Journal of Personality and Individual Differences, 11, 45-52.

Wood, R., \& Bandura, A. (1989). Impacts of concepts of ability on self regulatory mechanisms of complex decision making. Journal of Personality and Social Psychology, 56, 795-817.

Woodruff, S. L., \& Cashman, J. F. (1993). Task, domain, and general efficacy: A reexamination of the Self-efficacy Scale. Psychological Reports, 72, 423-432. 